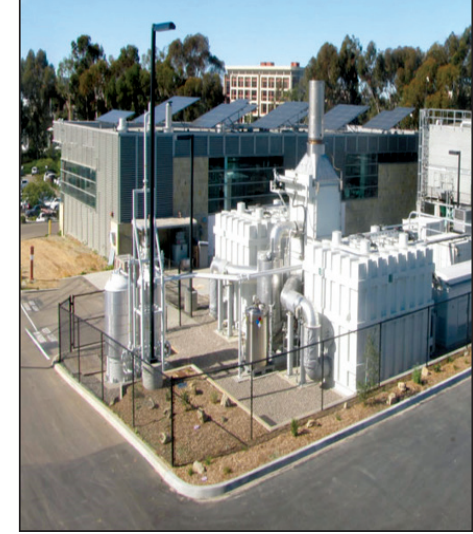

Fuel-cell-based power systems can be designed for high efficiency that can be further improved by hybridization. Efficiency improvements in solid-oxide fuel-cell/gas turbine hybrid systems are estimated to be exceptionally high. These hybrids can be incorporated into coal-based power plants to form a power system referred to as an integrated gasification fuel-cell system.

\title{
Future energy, fuel cells, and solid-oxide fuel-cell technology
}

\author{
By Nguyen Q. Minh \\ Feature Editor: Y. Shirley Meng
}

$\Lambda^{c}$ cording to the US Department of Energy's Energy Info mation Administration (EIA) (International Energy Outlook 2017), world energy consumption will increase $28 \%$ between 2015 and 2040, rising from 575 quadrillion Btu ( 606 quadrillion $\mathrm{kJ})$ in 2015 to 736 quadrillion Btu ( $\sim 76$ quadrillion $\mathrm{kJ}$ ) in 2040. EIA predicts increases in consumption for all energy sources (excluding coal, which is estimated to remain flat) - fossil (petroleum and other liquids, natural gas), renewables (solar, wind, hydropower), and nuclear. Although renewables are the world's fastest growing form of energy, fossil fuels are expected to continue to supply more than three-quarters of the energy used worldwide. Among the various fossil fuels, natural gas is the fastest growing, with a projected increase of $43 \%$ from 2015 to 2040 . As the use of fossil fuels increases, the EIA projects world energy-related carbon dioxide emission to grow from $\sim 34$ billion metric tons in 2015 to 40 billion metric tonnes in 2040 (an average $0.6 \%$ increase per year).

The projected energy consumption growth between 2015 and 2040 will come from the three end-use sectors, as analyzed by the EIA: $\sim 15 \%$ for the industrial sector (manufacturing, mining, agriculture, construction, and services), $\sim 27 \%$ for the transportation sector (light-duty vehicles, aircraft, buses, trucks, trains, and two- and three-wheel vehicles), and $\sim 31 \%$ for the buildings sector (residential and commercial structures).

Diverse energy forms are used in these sectors: liquids, natural gas, coal, renewables, and electricity (it should be noted that electricity is generated mainly from coal, natural gas, renewables, and nuclear; therefore, estimating energy consumption with electricity must take into account electricity-related energy losses). The share of each energy form varies depending on the end-use sector, as shown in Table I.

\begin{tabular}{|c|c|c|c|c|c|}
\hline & \multicolumn{3}{|l}{$\begin{array}{l}\text { Table I. Energy forms used in end-use sectors. } \\
\text { Energy form used, } \% \text { in } 2015 \text { (Projected } \% \text { in 2040) }\end{array}$} \\
\hline & Liquids & Natural Gas & Coal & Renewables & Electricity \\
\hline Industrial & $28(29)$ & $26(27)$ & $25(20)$ & $4(8)$ & $17(16)$ \\
\hline Transportation & $95(84)$ & $3(12)$ & - & - & $2(4)$ \\
\hline Buildings & $15(14)$ & $36(32)$ & $4(4)$ & $2(3)$ & $43(47)$ \\
\hline
\end{tabular}

Meeting this energy growth while limiting carbon dioxide emissions requires both efficiency improvements and emission reduction in the use of energy sources and generation/ transmission/delivery of electricity to the end-use sectors. "The challenge to satisfy future energy growth and at the same time curb carbon dioxide emissions necessitates different pathways and approaches in energy usage for both current and future energy systems," said Hae-Weon Lee, who has been working on different aspects of energy issues at the Korea Institute of Science and Technology. Without major changes or modifications in the way energy sources are used, most of the world's carbon budget up until 2040 would be spent by today's power stations, vehicles, and industrial facilities. Potential approaches may include development of cleaner and more efficient energy systems, expansion of sustainable energy technologies, increased use of certain methods such as carbon capture storage and utilization and clean fuels such as hydrogen, and efficiency improvement of current energy systems.

Fuel cells (FCs) could play a significant role in the efficiency improvement/emission reduction strategy. FCs (as energyconversion devices that produce electricity by electrochemical combination of a fuel with air) are clean (no combustion), efficient (direct conversion of chemical to electrical energy), and modular (independent scaling between power and capacity). FCs can be used for clean and efficient generation of electricity at different power sizes in industrial (e.g., MW FC power plants), transportation (e.g., $50-130 \mathrm{~kW}$ power for FC vehicles), and building (e.g., 1-5 kW micro combined heat and power or CHP) sectors. "Fuel-cell technology has three attractive features regarding its operation: operation on a variety of fuels, operation in reverse mode, and operation in tandem with other energy technologies," said Kazunari Sasaki, director of the Next-Generation Fuel Cell Research Center and director of the International Research Center for Hydrogen Energy at Kyushu University, Japan.

Although the primary fuel for FCs is hydrogen, FCs can operate on fossil and renewable fuels via reformation or, in some cases, direct utilization. FCs (with modifications in some cases) can also be operated in reverse mode (electrolysis) using electricity, for example, from renewable or nuclear energy sources to split water to produce hydrogen (clean and ef- 
ficient production of hydrogen) and, depending on the type of $\mathrm{FC}$, to convert mixtures of carbon dioxide and water to syngas (a potential method for carbon dioxide utilization). Reverse FC operation thus has been considered and developed for hydrogen production from water with affordable costs at distributed plant (e.g., $1500 \mathrm{~kg}$ hydrogen/day) and central station $(150,000 \mathrm{~kg}$ hydrogen/day) scales.

In addition, FCs can be combined with other power-generating equipment, such as a heat engine or a battery, to form a hybrid power system. In a typical hybrid combination, the heat engine uses the heat energy of the FC exhaust to generate additional electricity. One example is a hybrid configuration that incorporates a solid-oxide fuel cell (SOFC) with a gas turbine (GT). Hybridization of the SOFC with a GT significantly improves system efficiency, especially in large ( $\geq$ hundreds of kilowatts) power systems. Efficiency improvements in SOFC/GT hybrids are estimated to be exceptionally high in certain configurations, $>20$ points higher than the efficiency of an equivalent SOFC-only power system that is already better than GT-only systems.

SOFC/GT hybrids (or SOFCs only) can be incorporated into coal-based power plants to form a power system referred to as an integrated gasification FC (IGFC) system. "IGFC is a unique design configuration incorporating a new technology in a traditional energy system. It offers a potential pathway for use of coal in power generation in a cleaner and more efficient manner," said Suping Peng, academician at the Chinese Academy of Engineering, director of the State Key Laboratory of Coal Resources and Safe Mining, and director of the Solid Oxide Fuel Cell Center at the China University of Mining and Technology, Beijing. "IGFC is particularly relevant to regions like China, where coal is the main fuel source for power generation. The IGFC configuration

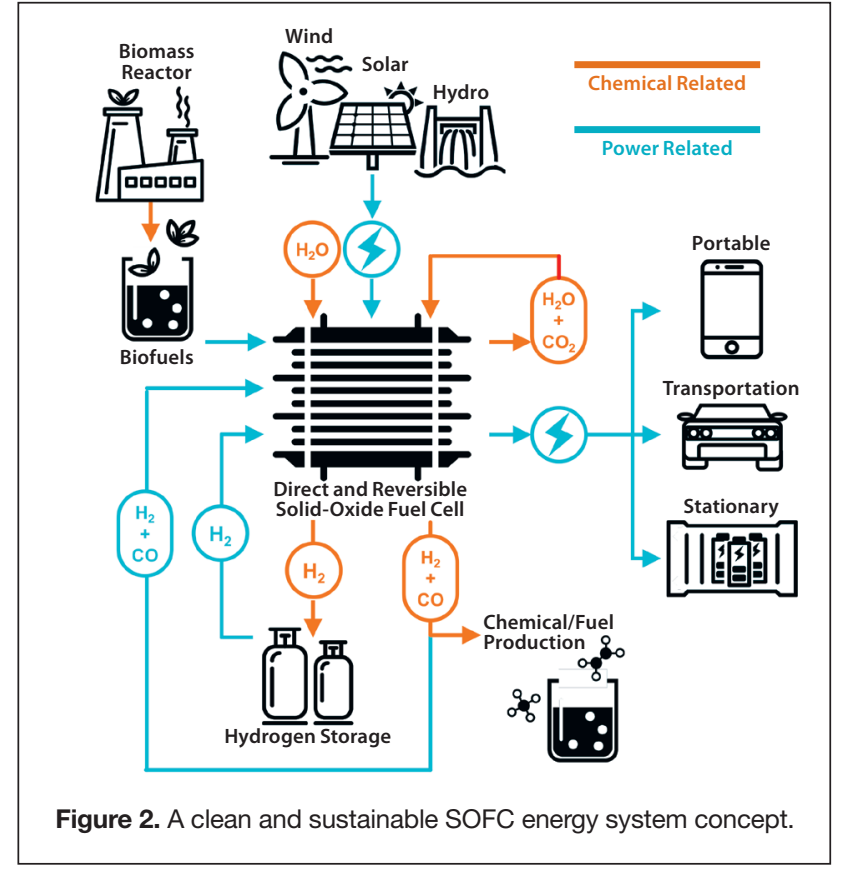

provides an opportunity for more efficient use of coal as well as easier capture of carbon dioxide," added Wei Chang, CEO of the National Institute of Clean and Low Carbon Energy in China.

Any future advanced energy systems should be flexible and compatible. Other desirable characteristics for such a system include those that are capable, adaptable, and affordable. One particular FC having all of these characteristics is the SOFC (Figure 1). "SOFC technology is environmentally compatible, fuel-flexible, multifunctional, and application-versatile; it could also be made cost-effective with large-scale commercialization. The SOFC is thus suitable to serve as a technology base for future energy systems," said Subhash Singhal, Battelle Fellow Emeritus, Pacific Northwest National Laboratory (retired) and member of the US National Academy of Engineering. Figure 2 shows an example of a system concept to illustrate the characteristics of SOFC technology shown in Figure 1.

FCs have made significant progress in the past 25 years since significant $R \& D$ began in the early 1990 s. Many of the applications for FCs are presently at the beginning or early stages of commercialization (e.g., 500 $\mathrm{kW}$ phosphoric acid $\mathrm{FC}$ and $\mathrm{MW}$-size molten carbonate FC power plants and several hundred $\mathrm{kW}$-size SOFC installations for buildings/facilities; $130 \mathrm{~kW}$ polymer electrolyte membrane fuel-cell [PEMFC] power for FC vehicles; and $1 \mathrm{~kW}$ PEMFC and SOFC CHP for residential homes). Other applications for FCs are at prototype, hardware demonstration, or conceptual design stages, depending on the specific type of FC, level of power output required, and other requirements. Although FCs possess many of the attractive attributes desirable for energy systems, FC commercialization is currently limited. Cost and durability are the most significant challenges. Further work in these areas is needed to move FCs toward widespread use for clean, efficient, and versatile energy systems.

Figure 1. Characteristics of an advanced SOFC-based energy system. 